\title{
O Grupo de Trabalho de Humanização e a humanização da assistência hospitalar: percepção de usuários, profissionais e gestores
}

I ${ }^{1}$ Adir Valdemar Garcia, ${ }^{2}$ Cleonete Elena Argenta, ${ }^{3}$ Kristiane Rico

Sanchez, ${ }^{4}$ Márcia Lange De São Thiago I

Resumo: O artigo apresenta uma reflexão em torno da temática da humanização da assistência à saúde, trazendo também os resultados de uma pesquisa que objetivou diagnosticar a eficácia dos Grupos de Trabalho de Humanização no processo de humanização da assistência a partir da percepção de usuários, profissionais e gestores. Trata-se de uma pesquisa de caráter exploratório, uma vez que levantou aspectos da realidade, caracterizandose por investigações de cunho bibliográfico, documental e investigativo. A pesquisa foi desenvolvida em dois hospitais públicos do estado de Santa Catarina, entre 2008 e 2009, e obteve-se como resultado que havia grande desconhecimento sobre a Política Nacional de Humanização e que os GTHs não estavam sendo eficazes no processo de humanização da assistência. Muitos dos limites apontados para que estes pudessem ser eficazes fugiam às possiblidades de atuação dos mesmos, pois relacionavam-se, principalmente, a questôes de âmbito político-administrativo mais amplas, bem como a características próprias da sociabilidade capitalista.

\author{
1 Pesquisador da Escola de \\ Saúde Pública de Santa Catarina \\ (ESP/SES/SC) e professor das \\ Faculdades Energia (FEAN); \\ Pedagogo; Especialista em \\ Educação; Mestre em Educação \\ e Doutor em Sociologia Política. \\ Endereço eletrônico adirvg@ \\ yahoo.com.br \\ ${ }^{2}$ Enfermeira e pesquisadora da \\ ESP/SES/SCe; especialista em \\ Gerontologia e Metodologia \\ do Ensino para Enfermagem. \\ Endereço eletrônico: cleonete@ \\ saude.sc.gov.br \\ ${ }^{3}$ Administradora e diretora \\ da Escola de Saúde Pública \\ de Santa Catarina Prof. MSc \\ Osvaldo de Oliveira Maciel; \\ mestre em Administração. \\ Endereço eletrônico: \\ kristianesanchez@hotmail.com \\ ${ }^{4}$ Assistente Social; \\ coordenadora da Divisão de \\ Gestão Escolar da Escola de \\ Saúde Pública de Santa Catarina \\ Prof. MSc. Osvaldo de Oliveira \\ Maciel; especialista em Serviço \\ Social na Área da Família e em \\ Desenvolvimento de Recursos \\ Humanos em Saúde. Endereço \\ eletrônico: m.lange@gmail.com
}




\section{Introdução}

A constituição da saúde pública no Brasil, assim como a consagração de uma série de outros direitos, é resultado das lutas travadas no seio da sociedade por suas classes sociais. Mas isto não significa que os "ganhos" obtidos pela classe dos trabalhadores e por aqueles postos à margem da sociedade e que constituem os "sem trabalho" resultaram unicamente da força destes. Cabe salientar que o próprio capital exige determinadas condições para seu desenvolvimento e, neste sentido, as políticas de educação e de saúde desempenham papel fundamental. A evolução do capital exige trabalhadores capazes de lidar com as tecnologias constantemente renovadas, o que exige formação. Do mesmo modo, precisa de profissionais sadios para que o processo produtivo seja o mais rentoso. A população em geral também deve estar apta ao consumo e, para tal, educação e saúde também são fundamentais.

É necessário, porém, considerar a intenção de muitos em construir uma sociedade onde as condiçóes de vida da população possam ser aquelas consideradas "dignas". Em sua maioria, os movimentos neste sentido visavam e visam a controlar a produção e reprodução do capital e, com isso, "humanizá-lo". Essa não é uma história brasileira, mas a história do próprio capitalismo. Isto leva a crer que "humanizar o humano" é algo inerente à própria história humana.

O Sistema Único de Saúde (SUS) é resultado dessas lutas sociais. Apesar de ser considerado um grande avanço, não conseguiu, até o momento, responder ao que preconiza. A saúde pública no Brasil ainda tem sido protagonista de cenas inaceitáveis, considerando-se as condições técnicas e econômicas atuais. Filas, falta de atendimento, demora, serviços insuficientes e em geral mal estruturados, investimento insuficiente, trabalhadores insatisfeitos com suas condições de trabalho e salarial são elementos bastante comuns nesse cenário. Tudo isso gera uma insatisfação social para com o sistema público de saúde.

O Ministério da Saúde (MS), objetivando mudar esse cenário, dentre outras iniciativas, regulamentou, em maio de 2000, o Programa Nacional de Humanização da Assistência Hospitalar (PNHAH), já que os hospitais eram o alvo das maiores críticas. O PNHAH estimulou a criação dos Grupos de Trabalho de Humanização (GTHs) nas unidades hospitalares de todo o país, para que se pudesse discutir sobre o tema e avançar no que se refere ao atendimento hospitalar humanizado no SUS, considerando tudo e todos envolvidos neste processo (as 
equipes, os gestores, os usuários, os meios físicos). Propôs a humanização das

relações entre gestores, servidores e usuários no atendimento hospitalar por meio da constituição dos GTHs, que seriam os multiplicadores do processo de humanização desenvolvendo açôes neste sentido. Objetivava a melhoria da qualidade e eficácia da atenção dispensada aos usuários da rede hospitalar brasileira credenciada ao SUS, efetivando a integralidade da atenção, um dos princípios do sistema, bem como a modernização das relações de trabalho nos hospitais públicos.

Em 2003, o Ministério da Saúde instituiu a Política Nacional de Humanização (PNH), sendo que seus princípios, diretrizes, dispositivos e método indicavam uma nova forma de tratar a humanização nos serviços de saúde. A discussão em torno da humanização se ampliou, indo para além da estrutura hospitalar, o que implica um novo olhar sobre todos os aspectos que compóem o processo de produção da saúde. Portanto, a PNH constitui proposição distinta do PNHAH.

Investimentos têm sido feitos no sentido de divulgar a política, bem como fazer com que seja apropriada pelos atores sociais envolvidos no processo de humanização da saúde. No entanto, as análises sobre a efetividade e eficácia da PNH sobre a compreensão que os diversos atores envolvidos têm dela, bem como sobre a apropriação de seus princípios e diretrizes por parte desses, ainda são escassas.

$\mathrm{O}$ artigo ora apresentado traz reflexões teóricas sobre o assunto e apresenta os resultados de uma pesquisa desenvolvida em 2008/2009, que objetivou diagnosticar a eficácia dos GTHs no processo de humanização do atendimento prestado em hospitais públicos da Secretaria de Estado da Saúde de Santa Catarina, a partir da percepção de usuários, profissionais e gestores. O GTH é considerado um dispositivo fundamental da $\mathrm{PNH}$, visto seu caráter de estruturador do processo de humanização. Os resultados desta pesquisa podem ser utilizados como base para a análise de outras realidades, bem como para o desenvolvimento de outras pesquisas que se proponham a avaliar outros dispositivos da $\mathrm{PNH}$, o que auxiliaria muito numa avaliação da efetividade e eficácia desta política.

\section{A humanização da assistência hospitalar}

Falar de humanização impõe, necessariamente, tecer comentários a respeito de sua significação. Deslandes (2004) atenta para a dificuldade de lidar com o termo humanização, visto que este implica a necessidade de humanizar o humano. Tal dificuldade só pode ser equacionada ao se entender que só se é humano quando 
se expressam determinadas condutas. Decorre daí uma questão: a partir do que tais condutas se estruturam? Duas possibilidades têm recebido maior destaque na literatura: 1) tais condutas refletem a "natureza" humana. Neste caso, é necessário assumir que a natureza humana é "boa", ou seja, constitui-se de atributos capazes de possibilitar uma convivência harmoniosa e de respeito à vida, tomada como uma relação humanizada (ARRUDA, 2003); 2) tais condutas não refletem uma "natureza humana", mas expressam a construção histórica do ser humano e, neste caso, o resultado reflete as relações sociais historicamente estabelecidas (PUCCINI; CECÍLIO, 2004). Para esses autores, as ações humanas são pertencentes ao homem, sejam elas boas ou más, então, por que falar em humanizá-las? Entendem a humanização como a busca da "essência humana", que pode ser encontrada nas relaçôes sociais, das quais o homem é também um produto. A palavra humano aparece, então, como adjetivo contrapondo-se ao adjetivo desumano, e não como substantivo, contrapondo-se a não-humano.

Puccini e Cecílio (2004) afirmam que cresce a tendência de concretizar a humanização como um processo trazido de fora do homem como ser social. Para os autores, a humanização deve ser entendida como um aspecto da realidade humana que se transforma com o passar do tempo, assim como o próprio homem. Portanto, a humanização, neste caso, não é tomada como natureza humana, como busca da "essência perdida", mas como o conjunto das relações sociais. Neste sentido, esses autores, ao entenderem que a humanização é resultado das relações humanas historicamente construídas, diferenciam-se de Arruda (2003) que, por sua vez, entende que existe uma natureza humana (boa) e que a desumanização é resultado das relações sociais estabelecidas.

Para Puccini e Cecílio (2004), humanização não se limita a um conjunto de ações para amenizar as contradiçôes sociais, sendo necessárias rupturas que possibilitem ir além da satisfação das "necessidades necessárias", que para Marx são aquelas produzidas historicamente, buscando valorizar as "necessidades radicais" que, para Heller, são partes da constituição das "necessidades necessárias" do corpo social do capitalismo, mas impossíveis de serem satisfeitas dentro desta ordem. Ressaltam que o que se deve levar em conta é a finalidade, o potencial e a direção desse movimento para o enriquecimento humano, podendo intervir socialmente, colocando em jogo as amarras culturais, sociais, políticas e econômicas que travam a conquista de novos padrões universais e solidários de qualidade de vida. 
No que diz respeito à saúde, os autores afirmam que o movimento pela humanização, ao elevar-se da predicação moral para a preocupação com o direito à saúde, o que implica reorganizar serviços e práticas, incorpora a preocupação com a satisfação do usuário. A humanização/satisfação radical possibilitaria ir além da mensuração de graus quantitativos de satisfação, posibilitando a incorporação de opiniōes e reivindicações da população, contribuindo para uma tomada de consciência mútua dos profissionais e cidadãos de novas finalidades e projetos comuns para a saúde.

Apesar de todos os avanços no que diz respeito à área da saúde, Puccini e Cecílio (2004) lembram que a ética do direito à saúde, tomada de forma abrangente e radical, é antagônica à lógica social do capital. Para os autores, a proposição da humanização radical pode possibilitar transformações na estrutura social e nas relações sociais vigentes. Neste sentido, essa proposição ganha o caráter de "estratégia", pois pode ir além do seu papel de melhorar, especificamente, as relaçōes e condições materiais da assistência à saúde.

No caso da $\mathrm{PNH}$, não há uma perspectiva de transformação sistêmica radical, ou seja, a proposição de superação da ordem social do capital, mas sim a perspectiva de construção de relações sociais que garantam a "dignidade do ser humano”, especificamente nos serviços de saúde. Tal proposição não fica restrita a esse âmbito, mas este é o locus para seu desenvolvimento.

Para o Ministério da Saúde (2004, p. 6), o ato de humanizar é tomado como "ofertar atendimento de qualidade articulando os avanços tecnológicos com acolhimento, com melhoria dos ambientes de cuidado e das condições de trabalho dos profissionais." Isto implica, portanto, o cumprimento dos deveres do Estado no que diz respeito ao oferecimento de uma rede de serviços capazes de responder objetivamente às necessidades da população, em termos materiais, bem como de considerar a subjetividade dos envolvidos no processo.

Neste sentido, a humanização da assistência está intimamente imbricada com a condição de o Estado capitalista possiblitar, diretamente, a partir de uma estrutura pública, ou indiretamente, a partir da garantia de condições para que a população busque no mercado, a satisfação de suas necessidades relacionadas à saúde. Neste caso, se estaria tratando dos níveis de prevenção, tratamento e cura de doenças, pois, a considerar-se a compreensão de saúde como resultado de múltiplos determinantes, a discussão torna-se extremamente mais complexa. Por exemplo, a 
política de promoção da saúde, pós-Carta de Ottawa, implica a garantia de vários outros serviços para além dos diretamente relacionados à saúde.

Pode-se concluir que a busca da humanização do humano relaciona-se ao estabelecimento de relações sociais, objetiva e subjetivamente, que possibilitem uma "vida digna"; portanto, humanizar os serviços de saúde é condição para tal. A compreensão da humanização como reflexo das relações sociais historicamente estabelecidas expressa melhor a concepção de humanização da PNH. Mesmo que esta não traga em si uma proposição de transformação radical da ordem social, ultrapassa a noção de existência de uma "natureza humana". O que não se pode negar é que todas as vertentes explicativas da necessidade de humanizar o humano aspiram a um "modo diferente" de relação social. Cabe saber como esse "modo diferente" pode se estabelecer e o que isto implica.

Compreender o significado de "humanização", bem como as proposições para seu alcance, é fundamental para que se possa entender tal movimento no interior do sistema de saúde. Isto implica necessariamente desvelar o nível de compreensão de usuários, profissionais e gestores a este respeito, bem como avaliar o papel do GTH nesse processo. A seguir, procura-se detalhar brevemente o movimento de humanização da saúde no Brasil.

De acordo com Benevides e Passos (2005), a discussão da humanização no campo da saúde no Brasil já aparece, timidamente, na XI Conferência Nacional de Saúde ocorrida em 2000, cujo título era "Acesso, qualidade e humanização na atenção à saúde com controle social”. Nesse mesmo ano foi lançado o PNHAH.

A implantação do SUS expressa a existência do direito à saúde, cuja efetividade só é possível a partir do acesso das pessoas a uma série de outros direitos condicionantes, conforme especificado no artigo $3^{\circ}$ na Lei no 8.080/90 (BRASIL, 1990), que estão longe de serem garantidos, sendo que alguns não podem ser, como no caso do direito ao trabalho. Isto, por si só, é um nó quando se luta pela efetividade do direito à saúde.

A não-efetividade do direito leva ao descrédito e à desconfiança dos usuários para com os serviços públicos de saúde, exigindo do SUS respostas imediatas a uma série de questōes. As queixas relacionadas ao atendimento prestado pelo sistema de saúde não se referiam e nem se referem apenas à falta de medicamentos, condiçõos dos equipamentos, capacidade de atendimento e demora no agendamento das consultas e de exames. É frequente a crítica dos usuários ao modo como foram 
atendidos, aspecto este destacado por Merhy (1998). Para o autor, um modelo assistencial centrado no usuário e na defesa radical da vida implica o reordenamento das relaçôes entre as tecnologias leves e duras, mediadas pelas leves-duras, sendo que o território das tecnologias leves é base de atuação de todos.

Os GTHs se constituem a partir do PNHAH, assim como uma Rede Nacional de Humanização entre as instituições públicas de saúde. O Manual do PNHAH destaca que um hospital pode atingir níveis de excelência do ponto de vista tecnológico, mas ser desumano no que tange ao atendimento se trata os pacientes como simples objetos de intervenção técnica, desconsiderando suas angústias, temores e expectativas. A falta de informações sobre a condição do paciente também é uma forma desumanizada de atendimento. Considerando a realidade "desumana" do hospital, refletida na sua prática cotidiana, o Ministério da Saúde (2001, p. 5) defende que "humanizar a assistência hospitalar é dar lugar não só à palavra do usuário como também à palavra do profissional de saúde, de forma que tanto um quanto o outro possam fazer parte de uma rede de diálogo.”

Referindo-se à baixa qualidade dos serviços, o manual do PNHAH destaca os problemas de comunicação dentro do sistema como um dos fatores determinantes. A boa comunicação entre profissional e usuário, bem como entre os profissionais, incluindo os gestores, é condição para o processo de humanização da saúde, segundo a maioria dos estudiosos (CAPRARA; FRANCO, 1999; OLIVEIRA; COLLET; VIEIRA, 2006).

Deslandes (2004) afirma que, apesar de se constituir como alicerce de um amplo conjunto de iniciativas, ainda não se tem uma definição mais clara do conceito "humanização da assistência". Na sua visão, este conceito tem se caracterizado mais como uma diretriz de trabalho, ou como um movimento de uma parcela de profissionais e gestores do que realmente como um aporte teórico-prático. Afirma que a noção de humanização é geralmente empregada para a forma de assistência que valorize a qualidade do cuidado no que se refere a questóes técnicas, associadas ao reconhecimento dos direitos do paciente, bem como de sua subjetividade e cultura. A noção de humanização implica ainda a necessária valorização do profissional e do diálogo intra e interequipes.

Deslandes (2004) destaca que um aspecto pouco explorado nos documentos do PNHAH são as condições estruturais de trabalho a que são submetidos os 
profissionais da área da saúde, normalmente mal remunerados e com uma carga considerável de trabalho. Neste sentido, a humanização da assistência tem que considerar a produção da assistência, humanizando-a.

Desconsiderar tal aspecto impossibilita operacionalizar uma assistência humanizada, pois se a proposta é humanizar o atendimento, não é possível pô-la em prática se aquele que presta o atendimento não estiver em condição para tal. Profissionais insatisfeitos com sua condição enquanto trabalhadores, em especial sua condição salarial e de participação na gestão dos serviços, sem condições de trabalho adequadas, com cargas horárias ampliadas por falta de profissionais ou como forma de complementação salarial, dificilmente estarão dispostos a refletir e a praticar o que é considerado um atendimento humanizado.

O PNHAH põe em cena uma discussão extremamente necessária. É preciso refletir sobre a humanização da assistência hospitalar. Porém, se mostrou limitado diante do problema que, por sua vez, ultrapassa a assistência hospitalar, atingindo o SUS em si. Isto implicou a necessidade de se pensar algo para além de um programa. Nasce, então, em 2003, a PNH, cujos princípios, diretrizes, dispositivos e método indicam um novo olhar sobre a necessária humanização da saúde.

A humanização é definida na PNH como valorização dos diferentes sujeitos implicados no processo de produção da saúde. A política traz como valores norteadores a autonomia e o protagonismo dos sujeitos, a corresponsabilidade entre eles, o estabelecimento de vínculos solidários, a construção de redes de cooperação e a participação coletiva no processo de gestão (BRASIL, 2008). São esses valores que embasam os princípios da $\mathrm{PNH}$, princípios esses que reforçam a necessidade de mudanças nas relações estabelecidas entre os envolvidos no processo de produção da saúde. Passa a ser fundamental a valorização da dimensão subjetiva e coletiva em todas as práticas de atenção e gestão no SUS, com a garantia dos direitos de cidadania; o fortalecimento do trabalho em equipe multiprofissional, com o fomento da transversalidade e da grupalidade; o apoio à construção de redes cooperativas, solidárias e comprometidas com a produção de saúde e com a produção de sujeitos; a construção de autonomia e o protagonismo dos sujeitos e coletivos envolvidos no processo; a corresponsabilidade desses sujeitos para com a gestão e a atenção; o fortalecimento do controle social em todas as instâncias gestoras do SUS; o compromisso com a democratização das relações de trabalho, bem como a valorização dos trabalhadores da saúde, estimulando processos 
de educação permanente em saúde; a valorização da ambiência, garantindo a organização de espaços de trabalho saudáveis e acolhedores (BRASIL, 2008).

A PNH tem como método a tríplice inclusão: inclusão dos diferentes sujeitos (trabalhadores, gestores e usuários); inclusão dos coletivos, inclusão dos fenômenos (analisadores) que desestabilizam os modelos tradicionais de atenção e de gestão. Os acontecimentos, fatos, fenômenos, se colocados em análise por um coletivo, fornecem subsídios para uma melhor compreensão dos limites de um determinado modelo de atenção à saúde, podendo ser encontradas soluções para estas limitações a partir desta análise coletiva.

Neste sentido, o objetivo é incluir pessoas e coletivos, visando ao compartilhamento do processo de construção de mudanças, o que leva à ampliação do próprio protagonismo e da corresponsabilização. Os "analisadores", por sua vez, resultam da inclusão de sujeitos e coletivos nos processos de trabalho, constituindo-se em elementos de tensionamento e, ao mesmo tempo, em forçamotriz da transformação que impulsiona análises das relações com intuito de buscar a efetividade da humanização.

Para além dos valores, princípios e método, a $\mathrm{PNH}$ apresenta diretrizes, quais sejam: acolhimento, fomento a redes e coletivos, gestão participativa e cogestão, defesa dos direitos e deveres dos sujeitos envolvidos na produção de saúde, clínica ampliada, valorização do trabalho e do trabalhador em saúde, ambiência e contextualização e produção histórica (BRASIL, 2008)

Essas diretrizes, por sua vez, precisam de dispositivos e arranjos de trabalhos que as traduzam em açóes concretas, quais sejam: colegiados gestores, acolhimento com classificação de risco, contratos de gestão, grupo de trabalho de humanização, câmara técnica de humanização, programa de formação em saúde do trabalhador, comunidade ampliada de pesquisa, apoio matricial especializado, equipe de referência, prontuário interdisciplinar, projeto terapêutico singular e projeto de saúde coletiva, projetos cogeridos de ambiência, visita aberta e direito a acompanhante, sistemas de escuta qualificada para usuários e trabalhadores da saúde, gerência de "porta aberta", ouvidorias, grupos focais e pesquisas de satisfação de usuários e trabalhadores, e projeto memória do SUS que dá certo (BRASIL, 2008). São esses valores, princípios, diretrizes e dispositivos, amalgamados pela metodologia da tríplice inclusão, que fazem da $\mathrm{PNH}$ um instrumento valioso na busca de maior qualidade no processo de produção de saúde para todos. 
Benevides e Passos (2005a, p. 570, grifo nosso) registram que a partir de 2004 ocorre uma ampliação significativa do raio de ação da $\mathrm{PNH}$, que parte do desenvolvimento de um intenso processo de discussões e pactuações envolvendo estados, municípios e serviços. Afirmam que dispositivos, a exemplo dos Grupos de Trabalho de Humanização e das Oficinas e atividades de apoio institucional, possibilitariam que a PNH se capilarizasse, resistindo às habituais determinaçôes verticais e normalizadoras do MS. Isto leva à compreensão de humanização do SUS

como processo de subjetivação que se efetiva com a alteração dos modelos de atenção e de gestão em saúde, isto é, novos sujeitos implicados em novas práticas de saúde. Pensar a saúde como experiência de criação de si e de modos de viver é tomar a vida em seu movimento de produção de normas e não de assujeitamento a elas.

O GTH caracteriza-se como um dos dispositivos da $\mathrm{PNH}$ cujo objetivo é intervir na melhoria dos processos de trabalho, bem como na qualidade da produção de saúde para todos (BRASIL, 2008a). É um dispositivo que deve instituir-se em qualquer instância do SUS, não se restringindo apenas aos serviços de prestação direta de assistência à saúde. Por isso, o MS faz referência aos GTHs ampliados ou Comitês de Humanização, onde se envolvem todas as instâncias gestoras vinculadas ao SUS, entidades formadoras, conselhos profissionais, usuários, etc. Devem ser formados por pessoas que tenham interesse em discutir os serviços prestados, a dinâmica das equipes de trabalho e as relaçôes que se estabelecem entre trabalhadores de saúde e entre estes e os usuários.

No caso específico deste artigo, tratar-se-á dos GTHs de hospitais públicos. Segundo a cartilha do Ministério da Saúde (2008a), os GTHs deveriam instituir uma "parada" e um "movimento" no cotidiano do trabalho para a realização de reflexão coletiva sobre o próprio trabalho, garantindo a voz a todos para poder dizer o que pensam, criticar, sugerir e propor mudanças no funcionamento dos serviços, na atenção aos usuários e nos modos de gestão. $\mathrm{O}$ objetivo seria aproximar as pessoas, possibilitando a transformação dos vínculos já instituídos, bem como estabelecer um ambiente favorável para compartilhar as tensôes do cotidiano, as dificuldades do trabalho e, por meio da análise e da negociação, possibilitar proposições inovadoras.

O GTH passa a ser visto como um instrumento de grande valia para que se possa fazer uma leitura do cotidiano do hospital e, ao mesmo tempo, um 
potencializador de atitudes voltadas para a melhoria da assistência. Junto com

os demais dispositivos, tem por função viabilizar os princípios e resultados esperados com o HumanizaSUS.

Essas breves observações a respeito do GTH são suficientes para mostrar sua importância. Afinal, cabe a este dispositivo intervir na dinâmica dos serviços com vistas à humanização dos mesmos. Sua função, tal qual a própria proposição de humanização da saúde, é extremamente complexa, pois implica lidar com diversos aspectos objetivos da organização e funcionamento dos serviços, bem como com as subjetividades de todos os envolvidos no processo.

\section{Metodologia}

Trata-se de uma pesquisa de caráter exploratório, uma vez que levantou aspectos da realidade, caracterizando-se por investigações de cunho bibliográfico, documental e investigativo, conforme Thiollent (2000). Portanto, é um estudo diagnóstico que tem como sustentação teórica um conjunto de literatura pertinente.

Foram analisados os GTHs de dois hospitais: Hospital Infantil Joana de Gusmão (HX) e Hospital Regional de São José (HY). Foram entrevistados: quatro representantes dos GTHs (dois em cada hospital); 12 usuários (seis em cada hospital); 17 gestores (oito no HX e nove no HY). As entrevistas seguiram roteiro semiestruturado e foram gravadas com anuência dos participantes. Os profissionais responderam a um questionário com questões abertas, semelhantes às dos roteiros de entrevista. Este instrumento foi entregue para $1 \%$ dos profissionais de cada setor dos hospitais, sendo que, a depender da estrutura do setor, no mínimo um deveria responder. No HX, foram distribuídos 57 questionários, sendo que 33 retornaram respondidos. No HY foram distrubuídos 68 questionários, retornando 31.

Para efeito de apresentação, a identificação dos hospitais e dos participantes da pesquisa foi feita através de letras e números. Os hospitais foram identificados por HX e HY; os gestores foram identificados como HXG1, HXG2, HXG3, HXG4, HXG5, HXG6, HXG7, HXG8, HXG9; e HYG, HYG2, HYG3, HYG4, HYG5, HYG6, HYG7, HYG8, HYG9; os usuários, por HXU1, HXU2, HXU3, HXU4, HXU5, HXU6; e HYU1, HYU2, HYU3, HYU4, HYU5 e HYU6; os profissionais que responderam os questionários foram identificados por HXP1, HXP2 ... e HYP1, HYP2 ... até o total de respondentes. 
A pesquisa foi desenvolvida em parceria entre a Universidade do Sul de Santa Catarina (UNISUL) e a Escola de Saúde Pública de Santa Catarina, pertencente à Secretaria de Estado da Saúde. Foi financiada pela Fundação de Apoio à Pesquisa Científica e Tecnológica do Estado de Santa Catarina (FAPESC). Cumpriu os requisitos éticos postos na Resolução no 196/96 do Conselho Nacional de Saúde, tendo sido aprovada pelos Comitês de Ética dos dois hospitais onde foi desenvolvida sob os protocolos 12/07 (Hospital Regional de São José) e 040/07 (Hospital Infantil Joana de Gusmão).

\section{Resultados e discussão}

Para alcançar o objetivo geral da pesquisa, ou seja, diagnosticar a eficácia do GTH no processo de humanização dos hospitais a partir da percepção de usuários, profissionais e gestores, foram levantados uma série de dados que, por limites deste artigo, não poderão ser especificados. Tais dados podem ser acessados em http://esp.saude.sc.gov.br, no link pesquisa, onde está disponíbilizado o relatório na íntegra. Far-se-á a apresentação de algumas falas, porém, os resultados serão apresentados de forma condensada, juntamente com a discussão dos mesmos.

Cabe destacar algumas informações sobre os dois GTHs, colhidas através de entrevistas feitas com dois membros de cada grupo. Foram escolhidos aqueles com maior tempo de participação e envolvimento com o grupo. O GTH do HX existia havia oito anos, considerando-se o PNHAH e quatro anos, considerandose a PNH. Todos os setores foram convidados a participar através de representação, porém o número de participantes nas reuniões do grupo girava em torno de dez a doze pessoas, mas efetivamente, de acordo com informações dos membros do GTH entrevistados, uns três ou quatro assumiam tarefas. O GTH do HY, por sua vez, existia havia dois anos, sendo que antes dele, um grupo também havia sido formado e funcionado por dois anos. O número de participantes variava de dez a 16 pessoas. A dificuldade de participação em função da dinâmica dos hospitais, principalmente em função do número reduzido de profissionais, foi um aspecto destacado pelas entrevistadas dos dois grupos.

A humanização dos serviços de saúde, em especial, do atendimento hospitalar, mostrou-se um assunto complexo, com várias implicações que vão desde a própria compreensão do que venha a ser a "humanização", até a operacionalização de algo que parece simples e que, na maioria das vezes, não se efetiva, a exemplo do 
estabelecimento de uma boa comunicação entre o usuário e o profissional, entre profissionais e entre estes e os gestores de saúde.

A Política Nacional de Humanização aparece no cenário da assistência à saúde como instrumento norteador de proposiçōes e ações voltadas para a humanização dessa assistência em função de diagnóstico que apontava para problemas os mais variados que geravam, e ainda geram, insatisfaçōes, não só por parte dos usuários, mas também de profissionais e gestores. O GTH, por sua vez, caracteriza-se como dispositivo fundamental para que o processo de humanização da assistência à saúde se efetive.

Concluiu-se que, para os usuários, profissionais e gestores participantes da pesquisa, a humanização estava diretamente ligada à busca de uma relação pautada no respeito, na garantia de direitos, na solidariedade, na ética, o que implicava acolhimento, colocar-se no lugar do outro, tomar o outro na sua completude e não apenas como um "corpo". Para tanto, era necessário também que as políticas de saúde fossem efetivas e permitissem oferecer um atendimento digno, que respeitasse as necessidades dos usuários, bem como dos trabalhadores da saúde. Neste sentido, a garantia de condições de trabalho, de um número suficiente de profissionais para atender à demanda, o oferecimento de salários que permitam que os trabalhadores possam se dedicar a um único emprego e a oferta de capacitação profissional foram elementos considerados fundamentais para a efetivação de uma assistência humanizada. Estes aspectos estão de acordo com as análises feitas por Deslandes (2004), Caprara e Franco (1999) e Oliveira, Collet e Vieira (2006).

A maioria dos usuários informou não saber exatamente o que seria a humanização. Poucos arriscaram uma opinião, sendo que se posicionaram quando questionados sobre o que seria um atendimento humanizado:

Eu entendo assim, não sei se é o certo. É estar unido, se unir com o paciente, médico com o paciente, ele ser mais calmo. O próprio profissional, né, o profissional enfermeiro, os técnicos de enfermagem. Eu acho que isso é uma união, um passando para o outro. Eu acho que tem que ter comunicação, né. Eu acho que faz parte da união. Não sei se é isso. (HYU5)

Um atendimento em que você chegue no local, seja bem atendido e resolva os seus problemas que ta se passando, principalmente com os atendentes, que são nossos filhos. (HXU3)

Ah, mais atenção, sabe, apoio às mães, pelo menos às que já estão há mais tempo e apoio às que chegam de fora, porque quando a gente chega aqui, a gente se sente perdida, sabe? Eu falo por mim, eu me senti muito perdida, longe de casa, a gente 
não recebe visitas todos os dias, então, a gente, às vezes, fica uma semana, 15 dias sem receber visita. E a gente se sente muito só. Sabe? Então, assim, hoje, alguns profissionais, como já conhecem o caso, já dão um pouco mais de atenção. Mas, no começo, eles são muito soberbos, não sentam, não explicam a doença da criança, o tratamento eles simplesmente jogam na tua mão e te vira. [...]. (HXU1)

É isso, atender com amor, atender com limpeza, com carinho, não é. Com respeito, com sorriso. Não um sorriso forçado, um sorriso verdadeiro. (HYUG)

\section{Em relação à concepção dos profissionais sobre humanização e atendimento} humanizado, as responstas foram bastante próximas das dadas pelos usuários, sendo a humanização, de modo geral, relacionada à valorização do ser humano:

Processo pessoal e coletivo de melhorar a qualidade no atendimento e prestação de serviços. Valorizar as pessoas (usuários e trabalhadores), melhoria da qualidade de trabalho para promover um melhor atendimento. (HXP4)

Entendo que humanização consiste em um processo de atendimento humanizado; assistir o paciente/família de uma forma integral, amenizando os sofrimentos, possibilitando a resolução de obstáculos. (HXP3)

São políticas voltadas para a melhoria dos aspectos ligados a melhor qualidade de vida, tanto de quem atende quanto de quem é atendido. (HXP29)

A humanização pressupõe respeito, troca, trabalho em equipe, valorização da busca coletiva de soluçôes com co-responsabilidade. (HYP3)

Compreende no final o bom atendimento ao cliente, mas passa por escutar, entender, respeitar clientes e funcionários e ter como tripé, a gestão participativa. (HYP30)

Servir o paciente com amor, como se estivesse atendendo a sua própria família. (HYP31)

Se colocar no lugar do paciente e no lugar do seu colega de trabalho, para saber como você gostaria de ser cuidado. (HYP10)

O usuário ser acolhido, receber orientações, ser assistido por uma equipe capacitada, ser atendido em suas necessidades de saúde; estar em um ambiente agradável, acolhedor, limpo... (HXP2)

Melhorar a relação entre paciente e funcionário. Chamar o paciente pelo nome. Respeitar os familiares. (HXP13)

Para os gestores, humanização e atendimento humanizado foram assim descritos:

Difícil. Humanização para mim é tratar o paciente, a família como um todo, acho que tem que tratar como um todo, respeitando os direitos, cobrando também os 
deveres deles, e o ambiente, eu acho também que a humanização não é só com o paciente, com famílias, aqui no caso, mas também com os funcionários do hospital e... eu acho que é isso. (HXG4)

Um atendimento humanizado? Eu acho que, muitas vezes, a gente tenta fazer aqui, mas nem sempre consegue, e até, às vezes, por falta de... atendimento humanizado eu acho que vai desde ter funcionários suficientes para trabalhar... uma das coisas que, às vezes, atrapalha é que a gente não tem gente suficiente na equipe, assim... que esse pessoal seja treinado para isso para, como eu falei, a gente, ficando com um número menor de pacientes, a gente pode dar essa atenção que eu acho que tem que ser e não só ficar aquela coisa técnica. A criança está recebendo medicação e tal, mas tu não tens um minuto para ouvir aquela mãe, ouvir aquela criança, se ela fala... enfim, prestar um pouco mais de atenção nisso. [...]. Eu acho que engloba tanta coisa se a gente for falar de humanização. Mas é isso, assim, ter tanto uma estrutura física quanto material para trabalhar, quanto uma equipe preparada, treinada, satisfeita, enfim, para que possa prestar esse cuidado que eu acredito que seja, não só o técnico, mas tudo o que envolve essa criança, essa família. É o que eu imagino que... (HXG8)

É, a humanização, entendo por um atendimento ético, um atendimento bem feito a todo ser humano, né? Independente de ser com o paciente, com os funcionários, com os próprios colegas de trabalho. Eu acho que a humanização, ela deve englobar, não somente o atendimento ao paciente, mas também dando qualidade para o trabalho dos servidores. Que eu acho que ta um pouco defasado. (HYG7)

No que diz respeito aos usuários dos dois hospitais pesquisados, verificou-se que a maioria estava satisfeita com o atendimento. As queixas que apareceram nas falas foram específicas, não pondo em xeque o sentimento de terem sido bem atendidos. A maioria também fez referência a melhorias na estrutura física, o que está relacionado diretamente à ambiência, um dos dispositivos da $\mathrm{PNH}$.

Eu achei que melhorou bastante do tempo que eu vinha no começo e hoje em dia, ta bem melhor. Assim, as cadeiras que as mães se sentam hoje... No começo a gente se sentava numa cadeirinha de plástico, passava noites e noites sentada numa cadeira daquelas de praia, daquelas branquinhas. Hoje não, hoje graças a deus, a gente tem aquele sofazinho, pode se esticar um pouco, né...descansar. Pra mim, melhorou bastante. (HXU2)

[...], eu desde que cheguei aqui de novo no hospital eu fui bem atendido já, me botaram prá fazer cirurgia, tudo, já me arrumaram quarto. Até agora estou sendo bem atendido. (HYU3)

Outra conclusão em relação aos usuários foi que nenhum dos entrevistados conhecia a PNH, sendo que poucos ofereceram uma explicação e apenas uma usuária disse ter observado informaçōes a respeito em cartazes afixados nos murais do hospital: 
Não sei se é um direito da gente, do... os direitos humanos da gente que... o direito que a gente tem adquirido pela lei que a gente tem... pode ser. (HXU3)

Ainda não. Esta é a primeira vez. Acho que é muito importante, acho que tem que estar presente em todos os hospitais, tem que estar presente. (HYU5)

Já. Eu estou vendo só agora em cartazes pelo hospital. (HXU1)

Da mesma forma, nenhum dos 12 entrevistados, apesar de seus vários atendimentos, conhecia ou tinha ouvido falar do GTH.

Não. Não conheço... pelo menos... posso conhecer as pessoas, mas não sei se eles trabalham exatamente nisso. (HXU1)

Não. Não conheço, já ouvi falar que tem uma organização que cuida, mas é o serviço dos voluntários. A única coisa que ouvi falar. (HYU2)

Considerando o completo desconhecimento dos usuários em relação aos GTHs, foi impossível verificar a eficácia dos grupos no processo de humanização do atendimento, a partir das suas impressōes.

Em relação aos profissionais, verificou-se que havia um desconhecimento de muitos destes acerca da PNH e do GTH. Dos 64 profissionais que responderam ao questionário, apenas 19 haviam participado de reuniōes do grupo. As justificativas para a não-participação podem assim ser sintetizadas: falta de tempo, não ter sido convidado, número reduzido de profissionais no setor, falta de divulgação, não saber da existência do GTH, não saber que poderia participar, falta de oportunidade, desinteresse e falta de motivação.

De modo geral, pouco mais da metade dos profissionais dos dois hospitais achava que as ações do GTH tornaram, de algum modo, a assistência nos hospitais mais humanizada.

Promove ambiente mais acolhedor, resolutivo, seguro para o usuário e trabalhador, mas se deveria fazer muito mais, principalmente para o trabalhador. (HXP4)

Sim. Porque facilitam a vida dos doentes e seus familiares que estão passando por essa fase difícil. (HXP12)

Há uma fiscalização de acompanhantes, os funcionários ficam mais motivados, os funcionários têm ou adquirem "consciência" de que as pessoas doentes precisam ser tratadas com mais atenção e carinho. (HYP24)

Alguns responderam que a atuação do GTH não estava tornando a assistência mais humanizada: 
Não. Para tornar a assistência mais humanizada, o funcionário não deveria ter a necessidade de aumentar a sua jornada de trabalho para ter um rendimento mais digno. Deveria ter mais profissionais atuantes e um local mais digno e sem falta de materiais para a realização do trabalho. (HXP15)

Não. Vejo muita gente comentar: 'de que adianta humanização se os funcionários atendem mal?’ e entendo o comentário porque, não raro, temos que ver situaçóes desagradáveis de mau atendimento. Por outro lado, percebo que os profissionais da saúde trabalham com uma carga horária exaustiva, se sentem mal atendidos nas suas próprias demandas institucionais e isso acaba refletindo na relação com o paciente. (HYP14).

Cabe destacar que, para aqueles que julgaram que a assistência não havia se tornado mais humanizada em função da implantação do GTH, a justificativa para tal girava em torno, principalmente, do fato de as condiçôes de trabalho não terem melhorado, incluindo a condição salarial, mesmo que esta não tenha sido diretamente referida na maioria dos casos. Entende-se que a pouca referência ao descontentamento para com os salários se deva à própria compreensão de humanização dos profissionais, em que os aspectos subjetivos da relação profissional/usuário receberam maior destaque.

Da mesma forma, mais da metade tinha observado mudanças na dinâmica dos serviços, relacionadas às diretrizes da $\mathrm{PNH}$, após a implantação do GTH. Alguns fizeram referência a melhorias na estrutura física, o que está vinculado diretamente à ambiência. No entanto, estas melhorias foram atribuídas, mais ao trabalho dos voluntariados que atuavam nos dois hospitais do que dos GTHs ou do poder público. No entanto, poucos percebiam que o comportamento dos profissionais havia mudado após a implantação dos GTHs. Em relação a mudanças no comportamento dos usuários, estas foram mais observadas no HY. Nos dois hospitais, as mudanças observadas estavam relacionas a uma maior exigência dos usuários em relação aos seus direitos. Em relação ao HX, verificou-se que muitos dos profissionais expressaram um sentimento de "abandono" em função de as ações do GTH serem direcionadas prioritariamente aos usuários. O desconhecimento dos GTHs e a análise do trabalho destes por parte dos que os conheciam implicaram no fato de cerca da metade dos profissionais avaliarem que os GTHs não eram atuantes, o que implica questionamentos em relação a sua eficácia. 

conhecimento desses a respeito da PNH também era pequeno. Em se tratando de gestores, esta constatação é preocupante.

A maioria dos gestores dos dois hospitais disse conhecer o GTH, mas o grau de participação destes nos grupos era pequeno. Em relação à atuação dos GTHs, constataram-se diferentes opiniōes, sendo que entre os gestores do HX, mais da metade disse que o GTH era atuante. Já no HY, mais da metade achava que não era atuante. Porém, a maioria dos gestores, considerando os dois hospitais, achava que as ações que estavam sendo desenvolvidas pelos GTHs (visita de porta aberta, "posso ajudar", ouvidoria, açōes voltadas para a melhoria da ambiência, comemoração de datas especiais, acolhimento com classificação de risco) tornavam o atendimento mais humanizado.

Sim. [...] O que as pessoas acham quando eles... é uma coisa de noção de palavras... quando fala em humanização, humanização o pessoal pensa que é botar uma florzinha em cima do armário, fazer uma festinha para as crianças, ir dar um beijo e um abraço numa mãe que está chorando... isso faz parte, isso faz parte, mas não é essência da humanização em si. Como eu falei para ti no início, quando perguntou o que é humanização, a humanização é isso: é o atendimento humanizado, é o atendimento concreto, é o atendimento resolutivo, que essa pessoa saia do nosso atendimento com aquilo que ela veio aqui fazer [...]. Mas, então eu vejo assim, o GTH, o serviço de humanização está fazendo isso, está colocando para as pessoas o que realmente é. Porque antes da $\mathrm{PNH}$, ninguém tinha noção concreta do que é isso porque isso não tinha sido levado para os hospitais, não existia um grupo que trabalhava com isso com os funcionários, com os usuários. [...] era uma coisa muito de florzinha, muito de enfeite, muito... e realmente é o que as voluntárias fazem aqui no hospital, elas enfeitam o hospital, brincam com as crianças, e isso realmente o voluntariado faz a humanização sim, magnífica, na parte delas. Então, eu vejo que o funcionário tem que fazer é isso, é entender realmente o que é a humanização... tivemos uma aula ontem belíssima sobre acolhimento, nós vamos iniciar o acolhimento com classificação de risco na emergência e depois eu pretendo trazer isso para o ambulatório... tem que pensar como que a gente vai fazer, mas é importantíssimo isso, para que o paciente que realmente seja atendido com urgência, ele seja atendido com urgência e aquele que possa esperar ele vai esperar o seu atendimento. Então, isso é que o grupo de humanização com essas reuniões ta colocando isso para as pessoas, para os funcionários, para os usuários, para todo mundo que atua aqui dentro do hospital. Então, eu acho realmente que isso vai ter uma mudança muito grande, sabe? E a gente sabe que é um trabalho de formiguinha, que não é de uma hora para outra, de hoje para amanhã [...]. (HXG3)

Olha, eu acho que se tivessem prosseguimento, um envolvimento maior, eu acho que melhoraria sim. Porque a ouvidoria, a gente responde e depois assim, se tem algum problema, não segue em frente, pára, tem um certo ponto que para. Teria que ter assim, se tivesse um prolongamento, eu acho que funcionaria. Porque, às vezes, 
assim, há reclamação dos pais a respeito de funcionário, a estrutura física, então, se tivesse uma comissão, alguma coisa que trabalhasse junto com a gente na unidade para resolver aquele problema, muitas vezes, assim, é com razão as reclamações... eu acho que funcionaria. Mas o problema é que chega num certo ponto que pára, aí fica por isso mesmo. (HXG4)

Com certeza, depois que foi implantado o GTH a gente viu uma mudança gradativa no atendimento ao paciente e aos funcionários. (HYG1)

Olha, eu acho que é o começo. [...] Sem esse grupo já era pior, mas eu acho que ainda falta muito. (HYG7)

Percebe-se que, apesar dos limites apontados no desenvolvimento das ações, bem como o alcance restrito dessas, há ainda uma leitura de que algumas coisas mudaram e tornaram a assistência mais humanizada. Não são falas, em sua maioria, que demonstram conviç̧ão e empolgação, mas não negam um avanço, mesmo que incipiente.

Mais da metade dos gestores dos dois hospitais relatou ter percebido mudanças na dinâmica dos serviços após a implantação do GTH. No HX, foi observada maior mudança no comportamento dos profissionais após a implantação do GTH. Já no HY, a maioria achava que não ocorreram mudanças neste sentido. Em relação a ter havido mudança de comportamento dos usuários após a implantação do GTH, no HX a maioria disse não ter percebido. No caso do HY, pouco menos da metade percebeu mudanças. Em relação a mudanças nas instalações dos hospitais, pouco menos da metade dos gestores dos dois hospitais as tinha observado, sendo que alguns as atribuíram mais à ação do voluntariado do que aos GTHs.

De qualquer modo, as falas dos gestores indicaram uma divisão no que diz respeito à eficácia do GTH no processo de humanização da assistência prestada pelo hospital. No caso do HX, num cômputo geral, metade, sendo que parte com uma convicção menor, entendia que o GTH influenciava para a melhoria dessa assistência e a outra metade, a maioria assumindo um desconhecimento em relação ao grupo, achava que a influência era muito pequena ou nenhuma. No caso do HY, as falas dos gestores indicaram, a princípio, que o GTH era eficaz no processo de humanização da assistência prestada pelo hospital. Num cômputo geral, no que dizia respeito à verificação de mudanças na dinâmica dos serviços, no comportamento dos profissionais, no comportamento dos usuários e nas instalações do hospital, praticamente a metade havia percebido mudanças, 
apesar de não as terem especificado no que diz respeito à dinâmica dos serviços e ao comportamento dos profissionais.

Em ambos os hospitais, a falta de divulgação do GTH e das ações por ele encabeçadas, a impossibilidade de participação em função de não poder se ausentar do trabalho e a discordância em relação à forma como a PNH vinha sendo implantada, desprivilegiando o profissional, foram questōes destacadas pelos gestores.

Quando questionados sobre que fatores dificultavam a humanização da assistência, as falas de usuários, profissionais e gestores confluíram destacando problemas de comunicação, falta de profissionais e de condiçōes de trabalho, demanda excessiva, falta de atenção e amor na relação profissionais/usuários, descontentamento dos profissionais, baixa remuneração, área física inadequada, falta de educação, falta de capacitação, desconhecimento da PNH e do GTH, rotinas hospitalares rígidas, descaso dos governos para com a saúde, dentre outros mais específicos. As falas abaixo retratam algumas das opiniōes:

[...] Eu vou te explicar de uma maneira, eu não sei se tu vais entender: a confusão que os médicos fazem na cabeça das mães. Porque, às vezes, vem um, atende a gente; em seguida vem outro e diz outra coisa, sabe... daí aquele vai e vem outro, e no fim eles não explicam nada direito pra gente. Não sei se tu estás entendendo o que eu estou dizendo... Então, isso aí deixa a gente meio confusa, porque um fala uma coisa, outro fala outra. Aí, no fim aqueles médicos que já falaram, já sumiram, vem outro, troca de plantão, aí aquele vem e fala outra coisa pra gente, e fica aquela confusão toda, né? É meio complicado. (HXU2)

Capacitação (deficiência) dos colaboradores; número deficiente de trabalhadores e também desmotivação para o trabalho; condições de trabalho (ambiência, equipamentos, etc.). (HXP2)

É a falta de condições de os funcionários trabalharem. Nós estamos abaixo da crítica aqui, para teres uma ideia, nós temos um número insuficiente de pessoal, então o pessoal, ele fica muito cansado, esgotado. Ele, em função de hora plantão, trabalha mais do que deve, trabalha em dois empregos, eles chegam aqui aí eles têm que preparar medicação, cuidar de crianças, tudo isso induz ao erro, à falta de atenção com as crianças [...]. Então, tudo isso implica no atendimento. Realmente, é a correria do dia-a-dia desse pessoal. (HXG1)

Eu vejo, em primeiro lugar é aquilo, é assim, mais amor, mesmo que não tenha... Porque depende muito deles também, deles como eu digo... Os materiais para o trabalho deles, que ta faltando, às vezes. [...]. Eu acho que os enfermeiros responsáveis deveriam estar mais presentes e conversar mais com a gente. [...]. No $3^{\circ}$ andar, aqui, tem o XXX que é muito atencioso, ele vem, pergunta para a gente, cobra da gente se 
a gente tem alguma dor, orienta se a gente necessita de alguma coisa tem que chamar uma, duas ou três vezes. Nós aqui não podemos sentir dor, ele sempre diz, não podemos estar com dor. Então eles nos dão mais atenção e isso faz parte, é parte também da nossa recuperação. Então eu acho que é isso. (HYU5)

Falta de comprometimento dos funcionários; alta demanda de pacientes; falta de materiais adequados para o trabalho; estrutura física deficiente. (HYP10)

A não atuação de forma efetiva do GTH na instituição, ou seja, o GTH pode até estar desenvolvendo, ou reunindo-se para gerar açôes, mas estas não chegam aos serviços e menos ainda trazem benefícios. (HYP13)

Os fatores, é, vejo na área de saúde e isso é público e notória é a falta de recursos para a área de saúde. Teria que ter mais investimentos na saúde. [...] É realmente investir, porque o que nós precisamos para atender bem? Precisamos de equipamentos, precisamos de funcionários, materiais específicos e com qualidade para atender bem o usuário. (HYG9)

Pode-se perceber que alguns dos elementos que dificultam um processo de assistência humanizado se relacionam a posturas, tanto de profissionais como de usuários e gestores, em especial os relacionados à comunicação, à forma de tratamento que, segundo os participantes da pesquisa, deve ser pautada no respeito, no carinho. No entanto, patentes foram os limites impostos pela própria realidade, que não dependem exatamente de um trabalho interno de humanização, mas de uma atenção das autoridades para com a condição da saúde pública que, se pode ser avaliada em melhores condições que há 20 anos, ainda é extremamente precária em várias áreas, especialmente na hospitalar. O número insuficiente de profissionais, a falta de condições de trabalho, estruturas físicas inadequadas e baixos salários são exemplos claros.

Considerando-se o resultado desta pesquisa sugere-se:

- elaboração de uma estratégia eficaz de divulgação e reflexão acerca da PNH;

- maior divulgação dos GTHs em termos de funcionamento, proposição e avaliação das ações para um maior envolvimento dos usuários, profissionais e gestores;

- desenvolvimento imediato de estratégias governamentais que venham a sanar os problemas relacionados à estrutura (edificações e condições de trabalho: equipamentos, materiais de consumo); e ao corpo funcional (principalmente adequação do quadro funcional, bem como dos salários);

- organização de processos de educação permanente para todos os profissionais. 


\section{Conclusão}

A necessidade de investimento no processo de humanização da assistência à saúde é fundamental para a efetivação do SUS. Apesar de o tema humanização da saúde provocar debates, visto sua questão principal, ou seja, a necessidade de humanizar o humano, não se pode descartar a imprescindível reflexão em torno da condição da assistência. Neste sentido, a implantação e o aprimoramento dos dispositivos da PNH, em particular do GTH, são de suma importância. Apesar de a realidade investigada mostrar os limites do trabalho desenvolvido pelos GTHs analisados, é necessário destacar alguns avanços - afinal, verificou-se o relato de várias iniciativas exitosas que não podem ser desprezadas.

Por fim, espera-se que o artigo ora apresentado possa colaborar com a humanização da assistência à saúde, e que sirva de base para outros estudos que venham a empreender uma análise da $\mathrm{PNH}$.

\section{Referências}

ARRUDA M. Humanizar o infra-humano: a formação do ser humano integral: homo evolutivo, práxis e economia solidária. Petrópolis: Vozes, 2003.

BENEVIDES R.; PASSOS E. Humanização na saúde: um novo modismo? Interface - Comunicação, Saúde, Educação, v. 9, n. 17, p. 389-406, mar/ago 2005.

- A humanização como dimensão pública das políticas de saúde. Ciência \& Saúde Coletiva. v. 10, n. 3, p. 561-571, jul/set 2005a. Disponível em: <HTTP://wwwscielo.br/pdf/ csc/v10n3/a14v10n3.pdf>. Acesso em: 10 mai. 2007.

BRASIL. Senado Federal. Constituição (1988). Constituição da República Federativa do Brasil. Brasília: Senado; 1988.

. Lei 8.080 de 19 de setembro de 1990. Dispõe sobre as condições para a promoção, proteção e recuperação da saúde, a organização e o funcionamento dos serviços correspondentes e dá outras providências. Diário Oficial da União. 20 set 1990; Seção 1:018055.

CAPRARA, A.; FRANCO, A. L. S. A relação paciente-médico: para uma humanização da prática médica. Cadernos de Saúde Pública, Rio de Janeiro, v. 15, n. 3, p. 1-12, jul/set 1999. Disponível em: <http://www.scielosp.org/scielo.php?script=sci_arttext\&pid=S0102311X199900030002...> Acesso em: 17 abr. 2006.

DESLANDES, S. F. Análise do discurso oficial sobre a humanização da assistência hospitalar. Ciência \& Saúde Coletiva, v. 9, n. 1, p. 1-12, 2004. Disponível em: <http://www. scielo.br/cielo.php?script=sci_arttext $\&$ pid $=$ S1413-81232004000100002\&Ing...> Acesso em: 14 abr 2006. 
MERHY, E. E. A perda da dimensão cuidadora na produção da saúde: uma discussão do modelo assistencial e da intervenção no seu modo de trabalhar a assistência. In: CAMPOS C. R. et al. (Org.). Sistema Único de Saúde em Belo Horizonte reescrevendo o público. São Paulo: Xamã, 1998. p. 103-120.

BRASIL. MINISTÉRIO DA SAÚDE. Manual do Programa Nacional de Humanização da Assistência Hospitalar - PNHAH. Brasília: Ministério da Saúde, 2001.

. HumanizaSUS: Política Nacional de Humanização. A humanização como eixo norteador das práticas de atenção e gestão em todas as instâncias do SUS. Brasília: Ministério da Saúde, 2004.

. HumanizaSUS: documento base para gestores e trabalhadores do SUS. 3. ed. Brasília: Ministério da Saúde, 2008. . Grupo de Trabalho de Humanização. 2. ed. Brasília: Ministério da Saúde, 2008a.

OLIVEIRA B. R. G.; COLLET N.; VIEIRA C. S. A humanização da assistência à saúde. Revista Latinoamericana de Enfermagem, v. 14, n. 2, p. 277-284, mar/abr 2006.

PUCCINI, P.T.; CECÍLIO, L. C. O. A humanização dos serviços e o direito à saúde. Cadernos de Saúde Pública. Rio de Janeiro, v. 20, n. 5, p. 1-16, set./out. 2004. Disponível em: <http:// www.scielosp.org/scielo.php?script=sci_arttext \&pid=S0102-311X200400050002 ...> Acesso em: 14 abr. 2006.

THIOllent M. Metodologia da pesquisa-ação. 10. ed. São Paulo: Cortez, 2000. 
This paper presents a discussion on health care humanization, bringing the results of a research aimed at diagnosing the effectiveness of Workgroups of Humanization in the process of heatlh care humanization from the users', professionals' and managers' viewpoints. It is an exploratory research, in that it dealt with aspects of reality, and characterizes as a bibliographic, documental, and investigative study. The research was carried out from 2008 to 2009, and the data was collected at two public hospitals in the State of Santa Catarina. The results showed that the National Policy for Humanization was greatly unknown and that the Workgroups of Humanization were not effective in the process of health care humanization; many of the factors considered essential for the effectiveness of the process escaped their control, their possibility of implementing actions, since they were mainly related to issues within the broader political and administrative sphere, as well as the characteristics of the capitalist sociability.

> Key words: health; health care humanization; Health Care System; quality of medical care. 